\title{
Inter-Temporal Relationship Between The U.S. Stock Market And The Emerging Markets Of Asia
}

Jayen B. Patel (E-mail: jpatel@adelphi.edu), Adelphi University

\begin{abstract}
We found that each of the ten emerging stock markets of Asia generated both lower returns and higher risk than the U.S. stock market for the recent nine-year period of the study. Second, we find that the emerging markets of Asia have become more integrated with the U.S. stock market over this period. However, the three South Asian stock markets continue to be fragmented from the U.S. stock market, and therefore these markets appear to present risk reduction opportunities for U.S. investors.
\end{abstract}

Numerous researchers (for example, Lee and Kim (1993-94), Meric and Meric (1998)) report that, in recent years, we have witnessed increased integration of world stock markets, resulting in increased correlations among national stock markets. Additionally, Kim and Haque (2002), and Saunders and Walter (2002) have demonstrated that the emerging markets have become more integrated with the developed markets in recent years, and therefore the emerging markets should no longer be considered a separate asset class. Meric and Meric (1998) find that correlations among national markets actually increased substantially following the October 1987 stock market crash. Lee and Kim (1993-94) report that the correlations between the U.S. stock market and foreign markets generally increase during periods of instability. These findings are troublesome for U.S. investors, as the primary motivation for investing internationally is to reduce risk, especially during periods of high volatility in the domestic stock market.

Our findings support the conclusions of prior published reports indicating that, in general, emerging markets have recently become more integrated with the developed markets. However, we feel that some emerging markets may be uniquely different from others, even if, as in our sample, the markets all belong to the same geographical region. For example, the ten countries that are considered the emerging markets of Asia have unique characteristics. These ten nations have heterogeneous characteristics with regard to such attributes as political system, culture, population, and size of the economy. Therefore, these markets should be examined more carefully before concluding that they represent a homogenous group.

Recent reports indicate that approximately $\$ 20$ billion is invested by developed countries in securities issued in underdeveloped countries. It appears that the emerging markets of Asia attract the largest proportion of this investment. Most of these stock markets are extremely small and highly volatile in comparison with the U.S. stock market. However, investment in the stock markets of these countries has increased exponentially in recent years. This is because many believe that investments in these markets provide higher returns, albeit higher risks. Second, emerging stock markets are comparatively less integrated with the U.S. stock market than the developed stock markets are, and therefore provide greater opportunities for risk reduction by means of international diversification.

Readers with comments or questions are encouraged to contact the author via email. 
Our initial objective is to compare the risk and return of the ten emerging stock markets of Asia, and to compare the performance of these markets with that of the U.S. stock market. Second, we compare he level of integration of each emerging market with the U.S. stock market. We are particularly interested in examining the level of integration during the recent period of comparatively poorer performance in the U.S. stock market.

We collected monthly returns for all ten emerging stock markets of Asia from the Morgan Stanley Country Indexes (MSCI) web site. Each MSCI is the official price index of the emerging country and is reported in U.S. currency. Specifically, we collected index values for China, India, Indonesia, Korea, Malaysia, Pakistan, Philippines, Taiwan, Thailand and Sri Lanka. U.S. stock market returns for the same period are used for comparison purposes. The returns for all markets are for the nineyear period from January 1993 through December 2001. Therefore our overall sample period consists of 108 months of return observations for each country.

\subsection{Performance Over Recent Nine-Year Period}

Contrary to the conventional belief that emerging markets generate higher returns than do the markets of developed economies, we find that the U.S. stock market provided a higher return than each of the ten emerging Asian stock markets over the recent nine-year period. In fact, only four of the ten emerging Asian stock markets, namely India, Korea, Malaysia and Taiwan, generated positive returns for that period. The remaining six markets, China, Indonesia, Pakistan, Philippines, Sri Lanka and Thailand, had negative returns.

Table 1: Monthly Return Characteristics of Emerging Asian Stock Markets and U.S. January 1993 - December 2001

\begin{tabular}{lccc}
\hline & Mean Return & Standard Deviation & Number of Obs. \\
\hline China & -0.88 & 12.69 & 108 \\
India & 0.29 & 8.88 & 108 \\
Indonesia & -0.14 & 16.09 & 108 \\
Korea & 0.91 & 14.16 & 108 \\
Malaysia & 0.47 & 11.73 & 108 \\
Pakistan & -0.41 & 12.17 & 108 \\
Philippines & -0.27 & 11.08 & 108 \\
Sri Lanka & -0.13 & 10.45 & 108 \\
Taiwan & 0.86 & 10.94 & 108 \\
Thailand & -0.49 & 14.48 & 108 \\
U.S. & 1.00 & 4.22 & 108 \\
Note: $\quad$ Index returns are all in U.S. currency. &
\end{tabular}

All ten of the emerging Asian stock markets have higher volatility of returns than the U.S. stock market. When we compare among the Asian markets, the Indian stock market has the lowest volatility (8.88\%) whereas the Indonesian stock market has the highest volatility (16.09\%) for the period of the study. The standard deviations for the remaining eight countries are generally similar, as follows: Thailand (14.48\%), Korea (14.16\%), China (12.69\%), Pakistan (12.17\%), Malaysia (11.73\%), Philippines (11.08\%), Taiwan (10.94\%) and Sri Lanka (10.45\%).

\subsection{Two Sub-periods Defined by Asian Crisis}

Aggarwal (1999) states that the 1997-98 Asian economic crisis created negative pressure, not only in the stock markets of Asia, but throughout the world. According to Aggarwal, many of the emerging markets have similar characteristics: very developed industrial economies but relatively poorly developed financial markets and institutions. 
He further reports that the Asian crisis of the late 1990's had the following three interesting aspects: first, the crisis came suddenly; second, the speed of decline was rapid, and; third, the crisis affected the major industrial nations as well. Many observers considered the Asian economic crisis a primary reason for the 1997-98 instability in the financial markets of the U.S.

Kim and Haque (2002) observe that the East Asian countries were considered economic icons, and provided a prototypical formula for success in the developing world for many years. However the 1997-98 Asian crisis, which erupted in July 1997 in Thailand, expanded to other Asian nations, and then to Russia and Latin America, and eventually spread to the rest of the world. The authors explain that the domino effect of the crisis was a consequence of the fact that countries have become increasingly inter-connected with regard to both trade and investments, so that a downturn in one country now affects others and spreads globally. Kim and Haque demonstrate that the increased integration of the developing markets with the developed world has benefits as well as disadvantages. Access to capital from the developed world helps to stimulate economic development. Alternately, foreign capital reversals have had a negative impact on the developing economies; the 1997-98 Asian crisis is an example of this problem.

We have divided our data into two equal sub-periods of four and a half years. The first half period extends from January 1993 through June 1997, for a total of 54 months. As noted above, it is generally accepted that the Asian debacle, which eventually had an impact on economies throughout the world, started in approximately July of 1997. Therefore our second sub-period includes the turbulent period of the Asian crisis, from July 1997, and extends through December 2001, for a period of 54 months. In the following discussion of our results, we have identified the first subperiod (1/93 to 6/97) as Good Times and the second sub-period (7/97 to 12/01) as Bad Times.

Table 2: Monthly Return Characteristics of Two Sub-Periods

\begin{tabular}{lcccc}
\hline & $\begin{array}{c}\text { 1/93 to 6/97 } \\
\text { Good Times Mean }\end{array}$ & $\begin{array}{c}\text { Standard } \\
\text { Deviation }\end{array}$ & $\begin{array}{c}\text { 7/97 to 12/01 } \\
\text { Bad Times Mean }\end{array}$ & $\begin{array}{c}\text { Standard } \\
\text { Deviation }\end{array}$ \\
\hline China & 0.03 & 9.28 & -1.78 & 15.40 \\
India & 0.81 & 8.28 & -0.23 & 9.49 \\
Indonesia & 1.66 & 7.63 & 1.94 & 21.39 \\
Korea & 0.24 & 6.62 & 1.58 & 18.97 \\
Malaysia & 1.42 & 7.30 & -0.48 & 14.93 \\
Pakistan & 0.15 & 8.81 & -0.97 & 14.86 \\
Philippines & 1.48 & 8.72 & -2.03 & 12.87 \\
Sri Lanka & 0.64 & 8.21 & -0.90 & 12.32 \\
Taiwan & 2.31 & 10.45 & -0.59 & 11.32 \\
Thailand & -0.35 & 9.25 & -0.62 & 18.38 \\
U.S. & 1.41 & 2.85 & 0.60 & 5.25 \\
\hline
\end{tabular}

Note: Index returns are all in U.S. currency.

In Table 2, we report the means and standard deviations of returns for the two sub-periods. With the exception of Thailand, each of the Asian stock markets generated positive returns for the first sub-period. It is generally believed that this is the period when most of these countries opened up to foreign investors. Also, during the end of this period, that is, beginning in the summer of 1997, the initial phase of the crisis started in Thailand.

When we examine the second sub-period (Bad Times), nine of the ten emerging Asian stock market had negative returns, with Korea the only exception. Additionally, each of the ten markets had lower returns in the second period than in the previous period. 


\subsection{Correlation Analysis}

Meric and Meric (1995) studied the co-movement patterns of the world's nine leading stock markets for the period 1973 through 1992. The significance of the diversification benefits derived from investing internationally has historically been a popular research topic, according to Meric and Meric. They state that it is critical to examine the inter-temporal relationship of correlation patterns between international stock markets in order to determine the potential benefits. They add that we can use past co-movement patterns as appropriate proxies for the future only if these patterns have generally remained stable over time. Meric and Meric used correlation analysis and principal component analysis to study these relationship patterns. They conclude that the co-movement relationships among the world's nine leading stock markets have changed significantly over time.

In a later study, Meric and Meric (1998) compared the long-term co-movement patterns of the world's leading stock markets before and after the 1987 crash. They concluded that the correlations among the world stock markets increased considerably between these two time periods, resulting in reduced diversification benefits after the crash.

Meric, Leal, Ratner and Meric (2001) examined the co-movements of U.S. and Latin American stock markets before and after the $1987 \mathrm{crash}$. They found that these correlations rose over time, and that there was no significant benefit to holding diversified portfolios of Latin American stocks compared to a well-diversified portfolio of domestic U.S. stocks. The authors conclude that investors should carefully select stocks from different countries, rather than simply purchase a broad index of Latin American stocks.

We calculated Pearson's correlation coefficients between the U.S. stock market and each of the ten emerging markets of Asia over both of the sub-periods we identified earlier. During Good Times, the Indonesian stock market had the highest correlation (0.480) with the U.S. market, whereas Sri Lanka had the lowest correlation (0.078). The average correlation coefficient between the U.S. market and the ten Asian emerging stock markets is 0.174 for the period January 1993 to June 1997. Excepting Indonesia (0.480) and China (0.308), the remaining eight countries had correlations with the U.S. market ranging between 0.078 (Sri Lanka) and 0.149 (Thailand). The three countries whose markets had the lowest correlations with the U.S. market are the South Asian countries of India, Pakistan and Sri Lanka.

Table 3: Pearson's Correlation Coefficients of U.S. Stock Market With Emerging Asian Stock Markets

\begin{tabular}{lcl}
\hline & $\begin{array}{c}\text { 1/93 to 6/97 } \\
\text { Good Times }\end{array}$ & $\begin{array}{l}\text { 7/97 to 12/01 } \\
\text { Bad Times }\end{array}$ \\
\hline China & $.308^{*}$ & $.463^{* *}$ \\
India & .096 & .256 \\
Indonesia & $.480^{* *}$ & $.382^{* *}$ \\
Korea & .143 & $.404^{* *}$ \\
Malaysia & .132 & $.333^{*}$ \\
Pakistan & .098 & .140 \\
Philippines & .140 & $.525^{* *}$ \\
Sri Lanka & .078 & .194 \\
Taiwan & .118 & $.456^{* *}$ \\
Thailand & .149 & $.560^{* *}$ \\
Average & .174 & .371 \\
\hline
\end{tabular}

Note: *. Correlation at the 0.05 level (2-tailed).

**. Correlation at the 0.01 level (2-tailed).
During the second sub-period, the average correlation coefficient increased from 0.174 (during Good Times) to 0.371 (during Bad Times). Our results are consistent with previously published findings indicating that correlations have increased in recent years, during periods that include turbulent times. The correlation coefficients with the U.S. market, from the first sub-period to the second sub-period, increased for every country except Indonesia. Recall that the Indonesian market had the highest correlation coefficient with the U.S. market during the first sub-period. In the second sub-period, Thailand had the highest correlation coefficient $(0.560)$ and Pakistan had the lowest correlation (0.140) with the U.S. market. Again, the stock markets of the three South Asian countries, India, Pakistan and Sri Lanka, continue to have the lowest correlations with the U.S. stock market.

Our analysis of the results derived from these correlations suggests the following two significant points. First, correlation coefficients have indeed increased during turbulent periods, and during recent years. Second, the markets of the three South Asian nations had lower correlations with the U.S. market for both sub-periods. Although it is larger in 
size than the markets of the other two South Asian nations, the Indian stock market generated substantially higher returns than either of these markets during each of the sub-periods.

Correlation analysis presents the results of bivariate return relationships between two countries, in our case, between the U.S. market and each of the emerging markets. We now want to extend our analysis by considering all of the stock markets simultaneously. Principal component analysis is a multivariate data analysis technique that allows us to examine simultaneously the relationships among all of the markets in our study. We are interested in determining which markets are segmented, and which are integrated, for the purpose of drawing conclusions about the extent to which diversification is enhanced by investing in these markets.

\subsection{Principal Component Analysis}

We report the results of our principal component analysis for the two sub-periods in Table 4. For the initial period (Good Times), principal component analysis identifies three components (factors) and indicates that the markets appear to be fragmented. The first component consists of the stock markets of Indonesia, Malaysia, Philippines and Thailand (all four Southeast Asian nations), China and Taiwan (East Asian nations) and Pakistan. This component explains $37.7 \%$ of the total variance of returns. The second component comprises the stock markets of India and Sri Lanka (South Asian nations), and explains an additional 15.6\% of the total variance. The third component represents the U.S. stock market, and explains an additional $10.4 \%$ of the total variance. The results indicate that these stock markets are segmented and that U.S. investors can reduce risk by investing in the emerging markets of Asia during periods of stability (Good Times).

The principal component analysis identifies three different groups. The first consists of the stock markets of all four Southeast Asian nations, two of the three East Asian nations (excluding Korea), and Pakistan. The markets of these seven nations move together and are highly correlated with one another. This grouping seems generally to be an intuitively logical grouping; the exceptions noted above are that the stock market of Korea (an East Asian nation) demonstrates a low correlation with this group while the stock market of Pakistan (a South Asian nation) is significantly correlated with this group. The second group consists of the markets of the two remaining South Asian nations, India and Sri Lanka. This group is uniquely different from both the other emerging Asian markets and from the U.S. market. The third component consists of only the U.S. stock market; this indicates that all of the emerging stock markets of Asia have lower correlations with the U.S. stock market and are viable candidates for diversification, at least during Good Times.

Table 4: The Principal Component and Factor Loadings of U.S. and Ten Emerging Asian Stock Markets

\begin{tabular}{|c|c|c|c|c|c|}
\hline & \multicolumn{3}{|c|}{ Panel A: 1/93 to 6/97 (Good Times) } & \multicolumn{2}{|c|}{ Panel B: 7/97 to 12/01 (Bad Times) } \\
\hline & PC. 1 & PC. 2 & PC. 3 & PC.1 & PC. 2 \\
\hline China & .755 & -.083 & .239 & .653 & -.077 \\
\hline India &.$\overline{408}$ & .679 & -.028 & .447 & .521 \\
\hline Indonesia & .766 & $\overline{.022}$ & .422 & .701 & -.132 \\
\hline Korea & .326 & .409 & -.191 & .627 & -.108 \\
\hline Malaysia & .741 & -.312 & -.129 & .744 & -.005 \\
\hline Pakistan &.$\overline{589}$ & .363 & -.343 & .289 & .826 \\
\hline Philippines & .823 & -.352 & -.179 & .808 & -.351 \\
\hline Sri Lanka &.$\overline{259}$ & .785 & -.010 & $\overline{.394}$ & .676 \\
\hline Taiwan & .584 & -.087 & -.254 & .750 & -.011 \\
\hline Thailand & .773 & -.309 & -.161 & .850 & -.201 \\
\hline U.S. & $\overline{.369}$ & .082 & .786 & .685 & -.087 \\
\hline Variance Explained & $37.7 \%$ & $15.6 \%$ & $10.4 \%$ & $42.8 \%$ & $14.7 \%$ \\
\hline Cumulative Variance & $37.7 \%$ & $53.3 \%$ & $63.7 \%$ & $42.8 \%$ & $57.5 \%$ \\
\hline
\end{tabular}


We find that the market integrates substantially during the second sub-period (Bad Times). During this period, we find only two principal components. The first component consists of the stock markets of: the four Southeast Asian countries (Indonesia, Malaysia, Philippines and Thailand), the three East Asian countries (China, Korea and Taiwan) and the U.S. This very interesting result, especially when compared to our results for Good Times, indicates that, in recent years, the U.S. stock market is no longer segmented from the markets of the Southeast and East Asian nations. Therefore, our findings are consistent with previous reports indicating reduced benefits from international diversification in recent years, and especially during turbulent times. However, we identify another important finding. The second component derived from our analysis is comprised of only the three South Asian nations of India, Pakistan and Sri Lanka. Our data support the conclusion that the U.S. stock market continues to be in a different group from the markets of the three South Asian countries, even during the recent periods of higher volatility and decreased returns. It appears that U.S. investors can reduce risk by investing in the three South Asian stock markets, even during periods of instability.

\subsection{Summary and Conclusions}

We examined two important features of the emerging stock markets of Asia. First, we find that the U.S. stock market generated higher returns, along with lower volatility, compared to each of the ten emerging Asian markets during the recent nine-year period, January 1993 through December 2001. This result did not change qualitatively when we divided the data into two equal sub-periods. Second, we find that the correlations between the U.S. stock market and each of the emerging markets have indeed increased over the recent period of greater volatility. However, we also find that, in recent years, the U.S. stock market remains in an asset class separate from the three South Asian stock markets of India, Pakistan and Sri Lanka. We cautiously suggest further investigation into the South Asian stock markets in order to examine whether these markets do indeed represent viable future investment destinations for U.S. investors.

I would like to thank R. Bruce Swensen for helpful comments.

\section{References}

1. Aggarwal Raj (1999), "Restoring Growth in Asia After the Late 1990s Economic Crisis: Need for Domestic and International Economic Reforms,” Multinational Business Review, Fall 1999, pp. 22-31.

2. Hair, Joseph F. Jr., Rolph E. Anderson, Ronald L. Tatham (1987). "Multivariate Data Analysis With Readings, Second Edition, Macmillan Publishing Company.

3. Kim, Suk H. and Mahfuzul Haque (2002), "The Asian Financial Crisis of 1997: Causes and Policy Responses," Multinational Business Review, Spring 2002, pp. 37-44.

4. Lee, Sang Bin and Kim Kwan Jung (1993-94), "Does the October 1987 crash strengthen the co-movements among national stock markets?," Review of Financial Economics, Volume 3, Fall 1993/Spring 1994, pp. 89102.

5. Meric Gulser, Ricardo P. C. Leal, Mitchell Ratner and Ilhan Meric, (2001). "Co-movements of U.S. and Latin American Equity Markets before and after the 1987 crash," International Review of Financial Analysis, Volume 10, pp. 219-235.

6. Meric Ilhan and Gulser Meric, (1998). "Correlations Between the World's Stock Markets Before and After the 1987 crash,” Journal of Investing, Volume 7, Issue 3, pp. 67-71.

7. Meric Ilhan and Gulser Meric, (1995). "Co-Movement Patterns of the World's Nine Leading StockMarkets," American Business Review, pp. 106-112.

8. Saunders, Anthony and Ingo Walter, (2002). "Are Emerging Markets Equities a Separate Asset Class," The Journal of Portfolio Management, pp. 102-114. 